\title{
Sumoylation of Vimentin ${ }_{354}$ Is Associated with PIAS3 Inhibition of Glioma Cell Migration
}

\author{
Liming Wang1,2, Jian Zhang3, Sipra Banerjee², Laura Barnes ${ }^{4}$, Venkateswara \\ Sajja ${ }^{4}$, Yiding Liu ${ }^{5}$, Baochuan Guo ${ }^{5}$, Yuping Du' ${ }^{1}$, Mukesh K. Agarwal ${ }^{6}$, David N. \\ Wald', Qin Wang', Jinbo Yang ${ }^{1,4}$ \\ ${ }^{1}$ School of Life Science, Lanzhou University, Lanzhou, P. R. China \\ ${ }^{2}$ Department of Cancer Biology, Lerner Research Institute, The Cleveland Clinic Foundation, Cleveland, USA \\ ${ }^{3}$ Tartis, Inc., Buffalo, USA \\ ${ }^{4}$ Molecular Genetics, Lerner Research Institute, The Cleveland Clinic Foundation, Cleveland, USA \\ ${ }^{5}$ Department of Chemistry, Cleveland State University, Cleveland, USA \\ ${ }^{6}$ Invenio Therapeutics, Inc., Cleveland, USA \\ 7 Department of Pathology, Case Western Reserve University, Cleveland, USA \\ Correspondence to: Jinbo Yang Ph.D, e-mail: yangj@ccf.org \\ Keywords: SUMOylation, vimentin, PIAS3, glioblastoma cell migration
}

Received: September 30, 2010, Accepted: November 10, 2010, Published: November 11, 2010

Copyright: ( ) Wang et al. This is an open-access article distributed under the terms of the Creative Commons Attribution License, which permits unrestricted use, distribution, and reproduction in any medium, provided the original author and source are credited.

ABSTRACT:

\begin{abstract}
The invasive phenotype of glioblastoma multiforme (GBM) is a hallmark of malignant process, yet the molecular mechanisms that dictate this locally invasive behavior remain poorly understood. Over-expression of PIAS3 effectively changes cell shape and inhibits GBM cell migration. We focused on the molecular target(s) of PIAS3 stimulated sumoylation, which play an important role in the inhibition of GBM cell motility. Here we report, through the immunoprecipitation with SUMO1 antibody, followed by proteomic analysis, the identification of vimentin (vimentin ${ }_{354}$ ), a nuclear component in GBM cells, as the main target of sumoylation promoted by PIAS3.
\end{abstract}

\section{INTRODUCTION}

Glioblastoma multiforme (GBM) represents 29\% of all primary brain tumors or 5,000 new cases per year in the United States [1]. The infiltrative growth pattern of these tumors precludes curative neurosurgery and no therapeutic modality has substantially changed the outcome of patients with GBM [2]. GBM spread by active cell migration rather than by passive, hematogenous spread [3-5]. A main characteristic of GBM is the cells' extreme migration potential and topographical diffuse nature, resulting in the inability to completely dissect GBM tumors [6]. New effective therapeutic modalities for advanced and invasive GBM are desperately needed.

Protein Inhibitor of $\underline{A}$ ctivated $\underline{S} T A T \underline{3}$ (PIAS3) was first identified as a specific inhibitor by blocking the DNA-binding activity of STAT3 and inhibiting STAT3mediated gene activation [7]. New evidence indicates that PIAS3 suppresses STAT3-mediated signal transduction by interacting with ATBF1 [8]. PIAS3 also acts as a binding protein of other transcriptional regulators such as androgen receptor, TIF2, and NF-kappaB [9]. Recent work has revealed that PIAS3 acts as an E3-like ligase to stimulate the attachment of small ubiquitin-like modifier (SUMO) to target proteins, which act in such important cellular pathways as Wnt signaling, the p53 pathway and steroid hormone signaling $[9,10]$.

PIAS3 induces apoptosis in prostate cancer cells both in vitro and in vivo [11]. When PIAS3 was overexpressed in GBM cells, complete suppression of growth and inhibition of cell migration was observed [12]. Considering the SUMO ligase activity of PIAS3, an obvious question is whether PIAS3-mediated sumoylation of regulators in apoptosis/migration pathways is involved in the inhibitory process. To characterize GBM's extreme migration potential, we focused on the effect of PIAS3stimulated sumoylation on the inhibition of GBM cell migration. 


\section{RESULTS}

\section{Ad/PIAS3 inhibit U373 cell migration}

When quiescent GBM U373 cells were infected with a low titer (5 pfu/cell) of Ad/PIAS3, the cell's morphology was changed, and cells became rounded and lost processes (Figure 1A). As demonstrated in the "artificial wound assay", a two-dimensional cell motility system [13], U373 cell migration was clearly inhibited compared with the cells infected by Ad/EGFP (Figure 1A). The inhibition of motility can be reflected by decreased cell number (Figure 1B) and reduced distance ( $\mathrm{F}$ polymerization at $72 \mathrm{OC}$ for igure 1C) migrated out from the origin of artificial wounding. The control cells have long processes toward the direction of movement. In contrast, Ad/PIAS-treated cells form few, if any, long processes, and such processes do not extend in forward direction.

To examine whether PIAS3 promotes sumoylation,
U373 cells were transfected with enhanced green fluorescent protein (EGFP)-tagged SUMO1 before infection. As shown in Figure 1D, PIAS3 did promote accumulation of EGFP-SUMO1 fusion proteins in the nuclei, reflected by increased intensity of green fluorescence in Ad/PIAS3-treated GBM cells.

\section{PIAS3 promotes Vimentin354 sumoylation}

The next question was what are the molecular targets of PIAS3-stimulated sumoylation, which play an important role in the inhibition of GBM cell motility. The PIAS3 had been mainly localized in nuclei $[9,12]$ and fluorescent EGFP-SUMO1 was accumulated in the nucleus upon PIAS3 stimulation. Unlike most sumoylated proteins identified by over-expressed tag-SUMO, our goal was to check the stimulatory effect of PIAS3 on endogenous SUMO. Then, agarose conjugated SUMO1 antibody (Santa Cruz) was used for immunoprecipitation (IP) of nuclear proteins. As shown in Figure 2B, the two

A

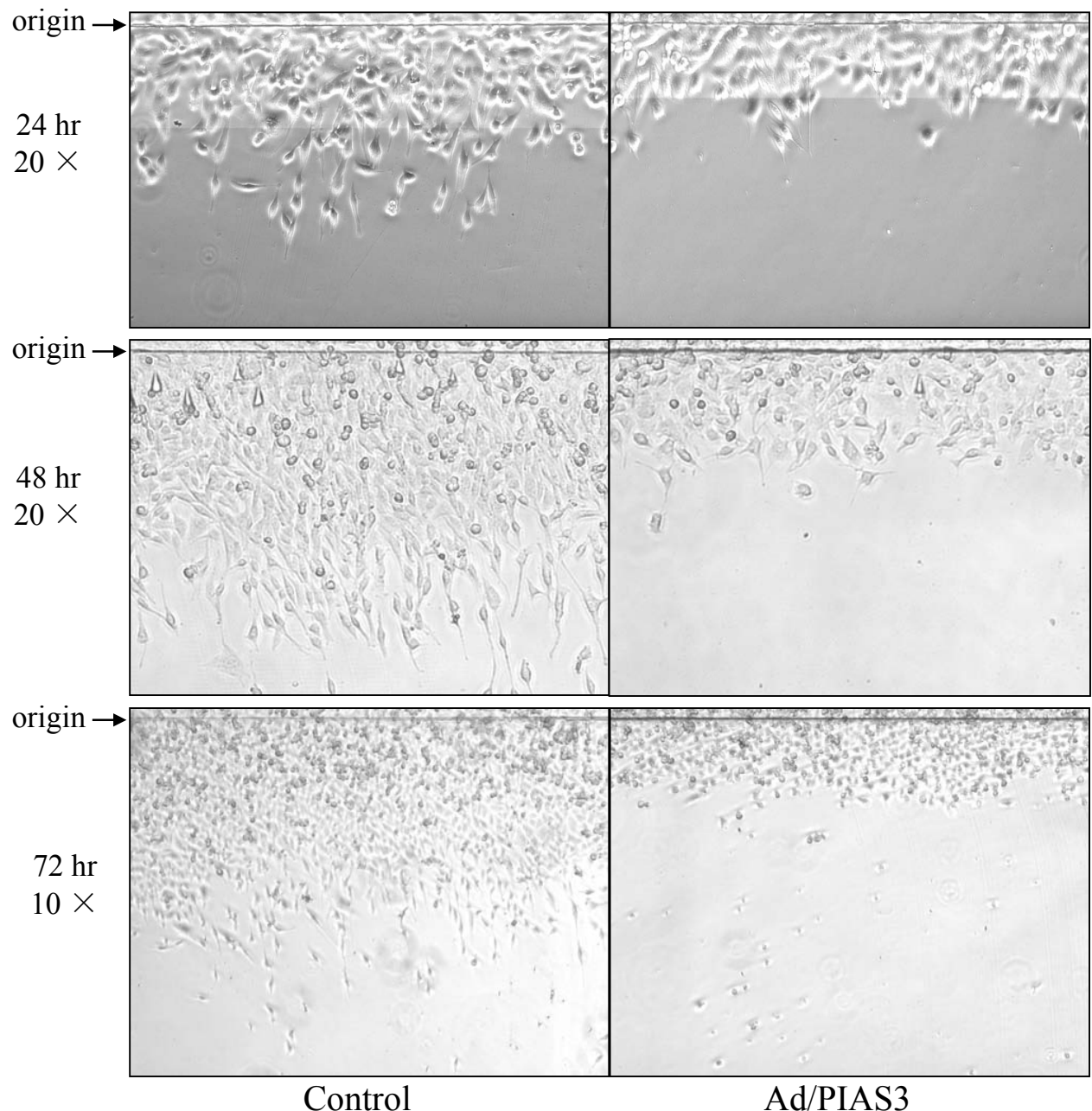

Figure 1. Inhibition of U373 cell migration by Ad/PIAS3. A. Confluent U373 cells were cut and lifted at the origin (arrow), and infected with $5 \mathrm{pfu} / \mathrm{cell} \mathrm{Ad} / \mathrm{PIAS} 3$. Images (original magnification $\times 10$ or $\times 20$ ) of migration were taken by phase contrast microscopy at the times indicated. Sizes of images are: $420 \times 210 \mathrm{~nm}$ for $24 \mathrm{hrs}, 420 \times 315 \mathrm{~nm}$ for $48 \mathrm{hrs}, 840 \times 630 \mathrm{~nm}$ for $72 \mathrm{hrs}$. 
B

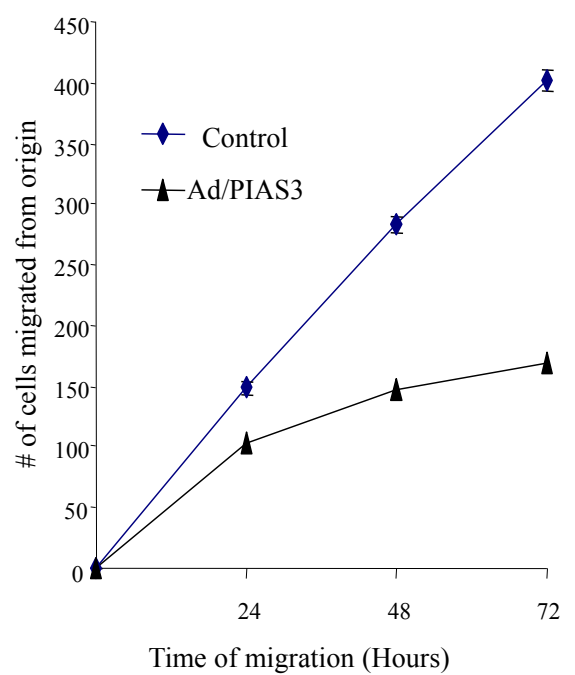

C

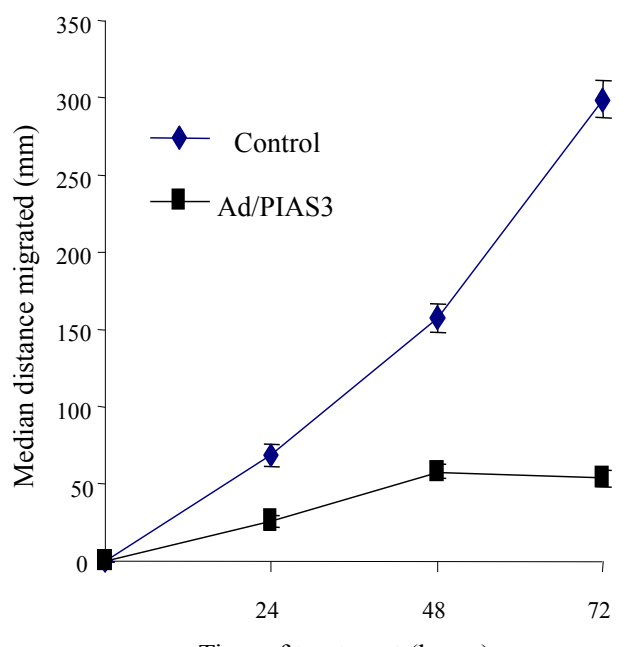

Time of treatment (hours)

Figure 1 B. Number of cells migrated out from the origin; C. Median distances of cells migrated from the origin. Ad/PIAS3 infected cells showed a decreased cell number and shorter distance in migration compared with control cells (mean of three independent experiments, Student's $t$-test $P<0.01$ ).
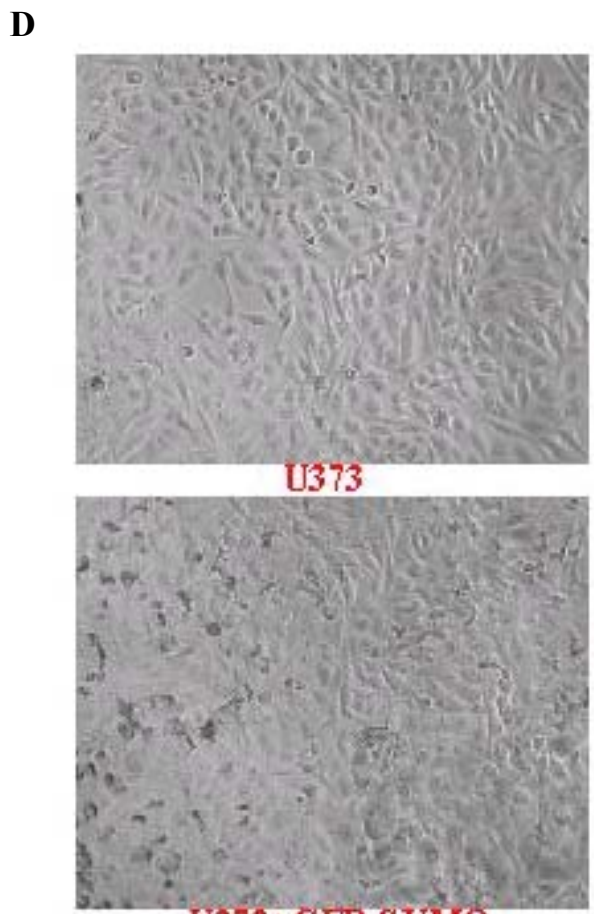

U373+GFP-SUMO

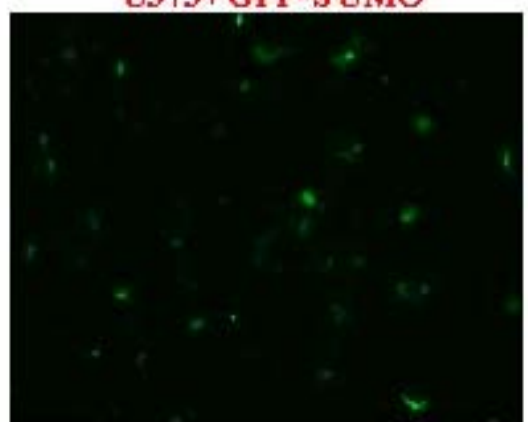

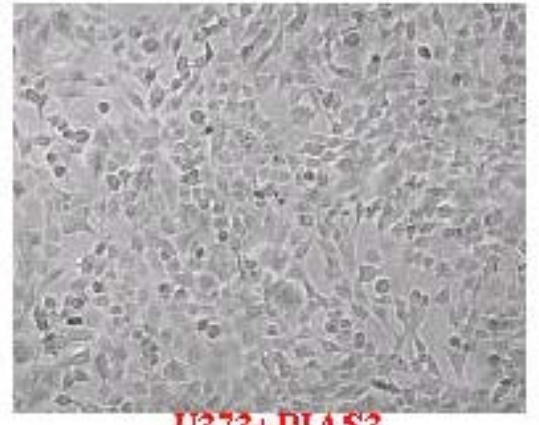

U373+PIAS3

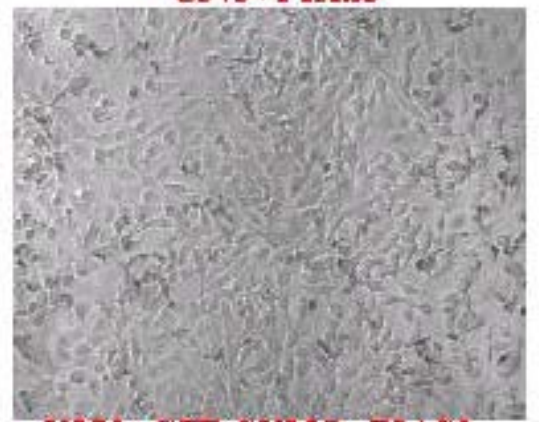

U373+GFP-SUMO+PIAS3

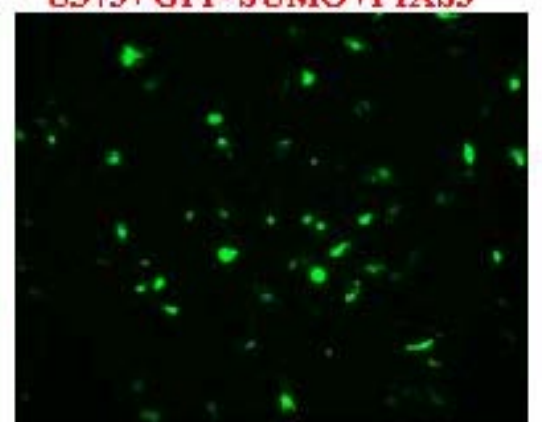

Figure 1 D. PIAS3 promotes sumoylation in U373 cells. Phase-contrast microscopic images collected 24 hours of control (U373), Ad/ PIAS3 infected (+ PIAS3), EGFP-SUMO1 transiently transfected (+ GFP-SUMO), and Ad/PIAS3 infected U373 cells after EGFP-SUMO1 transfection (+ GFP-SUMO + PIAS3). Fluorescent EGFP-SUMO1 clearly demonstrated that PIAS3 increased SUMO1 expression and accumulation of EGFP-SUMO fusion protein in nuclei (lower 2 panels, respectively). 
Vimentin354 (gi:5030431) Matched peptides shown in Bold Red

1 REANYIDKVR FLEQQNKILL AELEQLKGQG KSRLGDLYEE EMRELRRQVD 51 QLTNDKARVE VERDNLAEDI MRLREKLQEE MLQREEAEST LQSFRQDVDN 101 ASLARLDLER KVESLQEEIA FLKKLHEEEI QELQAQIQEQ HVQIDVDVSK 151 PDSTAALRDV RQQYEIVAAK NLQEAEEWYK SKFADLSEAA NRNNDALRQA 201 KQESTEYRRQ VQSLTCEVDA LKGTNECLER QMREMEEKFA VEAANYQDTI 251 GRLQDEIQNM KEEMARHLRE YQDLLNVKMA LDIEIATYRK LLEGEESRIS 301 LPLPNFSSLN LRETNLDSLP LVDTHSKRTL LIKTVETRDG QVINETSQHH 351 DDLE
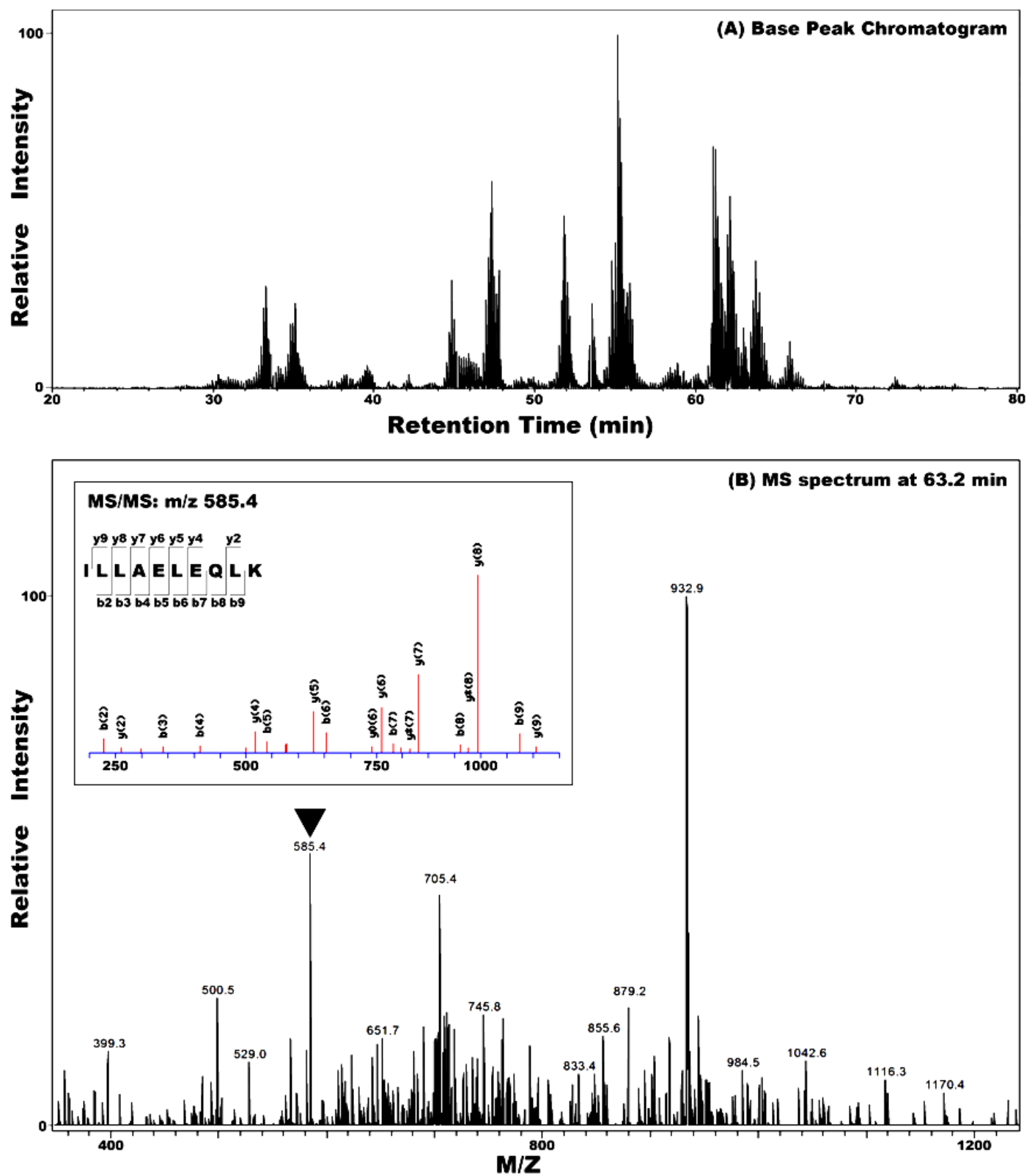

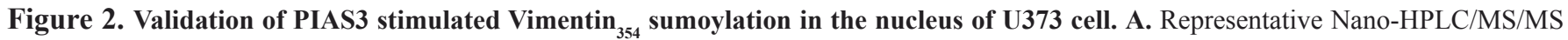
analysis for protein identification. The complete vimentine ${ }_{354}$ peptide sequence is given on the top panel. Middle panel: Nano-HPLC/MS/MS base peak chromatogram of the tryptic digests of gel slice in the mass range of $53 \mathrm{kDa}$; lower panel: MS spectrum at retention time of 63.2 min, and MS/MS spectrum of peptide ILLAELEQLK unique to the Vimentin ${ }_{354}$ protein. 
most prominent proteins, with molecular weights of about $53 \mathrm{kDa}$ and $86 \mathrm{kDa}$, can be identified by SUMO antibody in the Ad/PIAS3-infected cells, indicating that PIAS3 indeed promotes endogenous sumoylation of nuclear proteins. Because of the limited resolution of western blot results, we could not detect the presence of more sumoylated but less-abundant proteins by SUMO-IP.

Coomassie Blue-stained nuclear IP protein bands separated on polyacrylamide gel were excised, and protein in gel or the whole IP product on agarose beads was trypsinized. Then digested peptides were analyzed by high performance liquid chromatography and mass spectrometry/mass spectrometry (HPLC-MS/MS). Surprisingly, the vimentin ${ }_{354}$ (Accession No. AAA61281) [14] was identified in all four independent SUMO-IP followed by MS-MS analysis from two MS cores (Figure 2A). The molecular weight of vimentin ${ }_{354}$ is about 41.5 $\mathrm{kDa}$, when modified by SUMO1 (MW: $11 \mathrm{kDa})$, should move to $52.6 \mathrm{kDa}$. Western blot with goat anti-vimentin antibody confirmed the sumoylation of vimentin ${ }_{354}$, which was only found in the IP product of nuclear lysates (Figure 2B and C). Vimentin ${ }_{466}$ (Accession No. NP_003371, MW $53.6 \mathrm{kDa}$ ) was also identified from the band at about 86 $\mathrm{kDa}$, but failed to be recognized by goat anti-vimentin

B Cytosolic nuclear nuclear IP

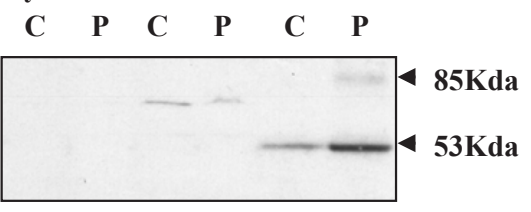

Blot: SUMO antibody. When the SUMO-IP pulled nuclear proteins from different time points were analyzed by western blot, vimentin $_{354}$ was found to decrease with time of Ad/PIAS3 infection, reducing to undetectable level after 48 hours (Figure 2D).

\section{DISSCUSSION}

Vimentin has been used as a molecular marker for GBM and astrocytomas [15-17]. Gene expression profiles assessed from laser capture-micro-dissected GBM cells have shown high levels of vimentin in the tumor core [18]. Theoretical analysis predicted two lysines with high probability (K261 and K201), and one lysine with low probability (K111) [19] as the putative SUMO site. Calculated from the molecular weight on western blot, only one SUMO was attached to vimentin ${ }_{354}$, result in the major band on SUMO-IP expected at $53 \mathrm{kDa}$. Sub-cellular localization of vimentin ${ }_{354}$ was predicted to be in the nucleus with $76.7 \%$ of reliability by theoretical calculation [20], which matched our observation. Compared with

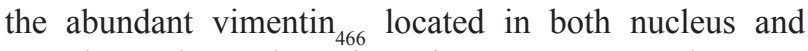
cytoplasm, the nuclear vimentin ${ }_{354}$ was expressed at very low level, therefore, vimentin ${ }_{354}$ could not be visualized by

C

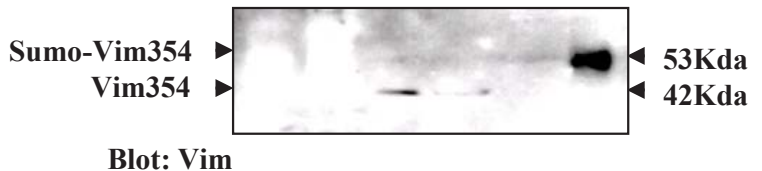

D

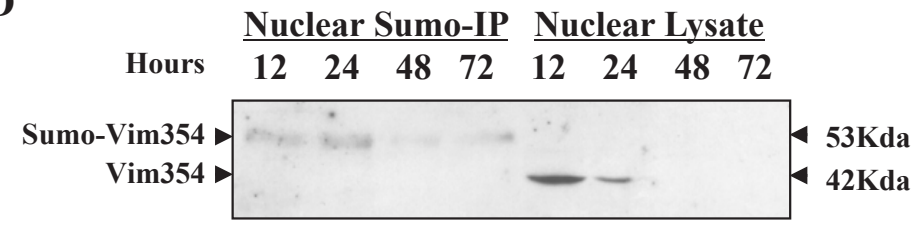

Blot: Vim

$\mathbf{E}$

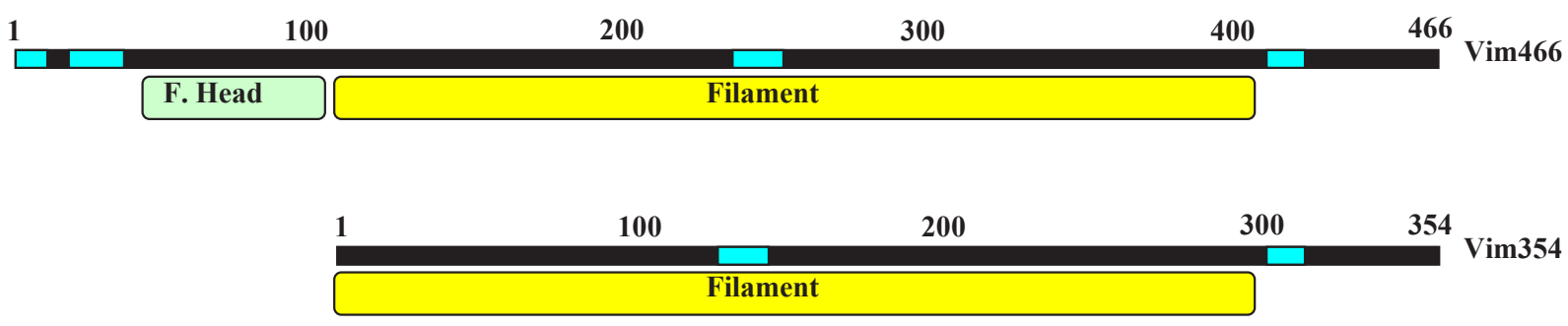

Figure 2 B \& C. Quiescent cells were infected with Ad/PIAS3 for 24 hrs and cytosolic or nuclear protein lysate was prepared. Then $80 \%$ of the nuclear protein immunoprecipitated by SUMO antibody (nuclear IP) from Ad/EGFP mock control (C) or Ad/PIAS3 (P) infected U373 cells were immunoblotted to demonstrate the same motility of both SUMO (B) and vimentin ${ }_{354}(\mathbf{C})$. Fifty microgram each of cytosolic and nuclear proteins was blotted to display the molecular weight of unmodified Vimentin ${ }_{354}$ at about $41.5 \mathrm{kDa}$. D. Sumoylation of nuclear vimentin ${ }_{354}$ at different time points after Ad/PIAS3 infection. E. Comparison of vimentin ${ }_{354}$ and vimentin ${ }_{466}$. With $91 \%$ of homology, each has a filament rod

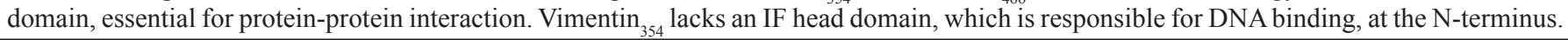


fluorescence immunohistochemistry (data not shown). The absence of lysine or arginine residues in the C-terminus of mammalian SUMO makes it difficult to map sumoylation sites [21], which may explain our failure to identify SUMO peptide in our MS/MS analysis.

Vimentin, as a primordial component of the cytoskeleton and the nuclear envelope, belongs to the class-III intermediate filaments (IF) found in mesenchymal cells. The de novo expression of vimentin is frequently involved in the epithelial-to-mesenchymal transition (EMT) associated with increased invasive/migratory properties of epithelial and cancer cells [22]. In prostate cancer cells, the level of vimentin expression has been correlated with cell motility, and the majority of poorly differentiated cancers and bone metastases showed high vimentin expression in tumor cells [23]. When vimentin was experimentally reduced, the cell's invasive potential could be effectively abolished in the in vitro Matrigel invasion assay [24]. Over-expression of vimentin in breast cancer model leads to augmentation of motility and invasiveness in vitro, which can be transiently downregulated by antisense oligonucleotides to vimentin [25]. Using an in vitro wound-healing model, it had been demonstrated that vimentin is transiently associated with, and could be functionally involved in the migratory status of breast epithelial cells [26]. Our observation hinted that sumoylation can be another way of removing functional vimentin, leading to the inhibition of GBM cell motility.

Compared with vimentin ${ }_{466}$, vimentin ${ }_{354}$ lacks 112 residues at the $\mathrm{N}$-terminus, representing the IF head (DNA binding) sequence, which is able to alter nuclear architecture and chromatin distribution. With 91\% homology to vimentin ${ }_{466}$ (Figure $2 \mathrm{E}$ ), vimentin $_{354}$ has the same B-Box-type zinc finger, zinc-binding domain, RING-finger (Really Interesting New Gene) domain, involved in mediating protein-protein interactions, which have a wide range of functions such as signal transduction and development. Migration is closely linked to cell shape and to mechanics of the cytoskeleton. Other than the current model of viscous fluid-like cytoplasm and elastic membrane to be the major load-bearing elements, the idea that "hard-wired" transmembrane receptors, cytoskeleton filaments (including vimentin), and nuclear scaffolds are responsible for cell shape control had been proposed [27]. Vimentin $_{354}$ may serve as the end connection molecule in the nucleus to hold the entire IF network, which is crucial for supporting the three-dimensional shape of the cell skeleton.

Post-translational modification by SUMO-1 is a highly conserved process in eukaryotic cells and plays important regulatory roles in many cellular processes. Since vimentin ${ }_{354}$ is the major target of endogenous sumoylation in the nucleus upon PIAS3 stimulation, it may play a key role in maintaining the normal cell shape and motility of GBM cells. Targeting the cell motility component actin had been proposed to combat cancer cell migration [28]. Our data suggest that vimentin ${ }_{354}$ may be added to the therapeutic target for fighting GBM.

\section{MATERIALS AND METHODS}

\section{Cell culture and Ad/PIAS3 infection}

Glioblastoma U373 cells were cultured in Dulbecco's modified Eagles medium (DMEM) containing 5\% fetal bovine serum and antibiotics. Cells were incubated at $37 \mathrm{C}$ in a humidified atmosphere containing $5 \% \quad \mathrm{CO}_{2}$. Adenovirus5 with PIAS3 was constructed. The entire coding sequence of human PIAS3 (Genbank accession number NM_006099) was amplified by RT-PCR, cloned into the pShuttle-CMV vector, and sent to Cleveland Clinic Foundation Virus Core for adenovirus construction and purification. Infection was performed by diluting the virus to the appropriate concentration in medium. Adenovirus5 vector was used as control.

\section{Cell count}

$50,000 \mathrm{U} 373$ cells were seeded in each well of 12well tissue culture plate, and infected with $100 \mathrm{pfu} / \mathrm{cell}$ Ad/PIAS3. Cells were trypsinized at different time points, and counted as total cell number or cell survival by trypan blue exclusion. The numbers of average and standard error are obtained from triplet wells.

\section{In-gel digestion of SDS-PAGE separated and coomassie-stained gel}

Coomassie-stained polyacrylamide gel containing protein bands of interest were excised. gels were destained with $50 \%$ acetonitrile in $100 \mathrm{mM}$ ammonium bicarbonate, and then $100 \%$ acetonitrile. The proteins were reduced in the gels with $20 \mathrm{mM}$ dithiothreitol (DTT) at room temperature for $30 \mathrm{~min}$, followed by alkylation with 50 $\mathrm{mM}$ iodoacetamide in $100 \mathrm{mM}$ ammonium bicarbonate for $30 \mathrm{~min}$ in the dark. After treatment, the reagents were removed and the gel pieces were washed with 100 $\mathrm{mM}$ ammonium bicarbonate and then dehydrated in acetonitrile. The dried gel pieces were then rehydrated in a solution of sequencing grade, modified trypsin in $50 \mathrm{mM}$ ammonium bicarbonate for digestion overnight. Tryptic peptides were extracted from the gel with $50 \%$ acetonitrile in 5\% formic acid. The LC-MS/MS analysis is performed on Bruker HCT 3000 plus ESI-IonTrap Mass Spectrometer coupled with Agilent 1100 HPLC system. An additional Shimadzu LC-10ADvp HPLC pump is used for sample loading. Tryptically digested sample is injected and first loaded onto a Rheodyne Peptide Captrap (Michrom BioResources, Inc.), then eluted through a 
capillary RP-HPLC column (10 cm long, $300 \mu \mathrm{m}$ ID, $5 \AA$ $\mathrm{C} 18$, from Grace Vydac). The elution gradient is: $2 \% \mathrm{~B}$ for $10 \mathrm{~min}$; 5\%-45\% B for $200 \mathrm{~min}$; 45\%-85\% B for 30min; $85 \% \mathrm{~B}$ for $30 \mathrm{~min}$. The ion-trap mass spectrometer is set in auto $\mathrm{ms} / \mathrm{ms}$ mode; number of precursor ions is 3 . The collected MS/MS data are processed (compound finding and deconvolution) by Bruker Data Analysis, version 3.1.

\section{Immunohistochemistry}

Slides of human normal organs and human various tumors were purchased from Imgenex. The paraffin was removed by xylene and followed by sequencial ethanol wash. Antigens were retrieved by boiling the slides for 5 minutes in $10 \mathrm{mM}$ Sodium Nitrate $(\mathrm{pH} \mathrm{6.0)}$ ) and rehydrated in PBS. The slides were first blotted in PBS with $0.5 \%$ BSA and $0.2 \%$ cold water fish gelatin (PBG), then incubated in PBG with anti PIAS3 antibody. Biotinylated secondary antibody and Streptoavidin conjugated with horseradish peroxidase (ABC kit, Vector Labs) were applied to the slides, color develop was achieved by using DAB kit (Vector Labs) following the manufacturer's instructions. All images were captured at the same light intensity, brightness and contrast.

\section{Human brain tumor RNA}

All original brain tumors were obtained from the Department of Neurosurgery, The Cleveland Clinic Foundation, and diagnosed as glioblastoma, astrocytoma and oligodendrocytoma by surgical pathology Pieces of fresh brain tumors were fast frozen in liquid nitrogen, and ground into fine powder for RNA isolation.

\section{Western blot}

The U373 cells were lysed in 1\% Triton X-100 lysis buffer containing protease inhibitors. Cell debris was removed by centrifugation. $20 \mathrm{mg}$ of protein from each sample was separated on SDS-PAGE gel, transferred to PVDF membrane, and blotted with anti PARP antibody. Positive bands on the blots were detected by using ECLPlus kit (Amersham-Pharmacia) following manufacturer's instruction.

\section{RT-PCR amplification of PIAS3 mRNA sequences}

Total RNA extracted from normal white matter and brain tumors was reverse transcribed to cDNA. PIAS3's coding sequences from nucleotide 1 to 861 was amplified by 35 cycles of denaturing at $95^{\circ} \mathrm{C}$ for 1 ', annealing at $55^{\circ} \mathrm{C}$ for $1^{\prime}$, and polymerization at $72^{\circ} \mathrm{C}$ for 1 ' $30^{\prime \prime}$. A 516 bp $\beta$-actin fragment was also amplified for quality control.

\section{Measurement of glioma cell motility}

Cell migration was measured by the 'artificial wound' method as described [8]. Confluent U373 cells in 12-well tissue culture plates were cut-lift (wound) with a razor and $50 \mathrm{pfu} / \mathrm{cell} \mathrm{Ad} / \mathrm{PIAS} 3$ was added to the medium for infection. Control cells were infected with Ad/GFP at the same concentration. A digital camera on phasecontrast microscope was used to capture images of cell migration. In each well, three random fields were chosen to count the number of cells that crossed the origin line and to calculate the median distance the cells migrated. The data from triplicate wells were expressed as the mean and standard error of the number of migrating cells, as well as the median distance. All experiments were done at least three times.

\section{CONFLICT OF INTEREST}

The authors declared no potential conflicts of interest.

\section{ACKNOWLEDGEMENTS}

We thank Dr. Ratan Maitra of Cleveland Clinic Foundation (CCF) for making Ad/PIAS3, and Jeff Y. Chang, Li Wang of CCF for technical assistance. The authors gratefully thank Drs. George Stark and Michael Vogelbaum of CCF for their support and helpful comments, and thank Christine Kassuba of CCF for editing the manuscript. This work is partially supported by a pilot grant from American Cancer Society, Cuyahoga Unit, to L. W; NIH grants HG01815 and CA81653 to B.G; NCET08-0260 from Ministry of Education and 2009DFA30990 from Ministry of Science and Technology of the People's Republic of China; 0708WCGA149 from the Gansu Provincial Science and Technology to J.Y.

\section{REFERENCES}

1. Mahaley MS Jr, Mettlin C, Natarajan N, Laws ER Jr, Peace BB. National survey of patterns of care for brain-tumor patients. J Neurosurg. 1989;71:826-36.

2. Maher EA, Furnari FB, Bachoo RM, Rowitch DH, Louis DN, Cavenee WK, DePinho RA. Malignant glioma: genetics and biology of a grave matter. Genes Dev. 2001;15:1311-33.

3. Sontheimer H. Malignant gliomas: perverting glutamate and ion homeostasis for selective advantage. Trends Neurosci. 2003; 26:543-49.

4. Khusial PR, Vadla B, Krishnan H, Ramlall TF, Shen Y, Ichikawa H, Geng J, Goldberg GS. Src activates Abl to augment Robol expression in order to promote tumor cell migration. Oncotarget 2010; 1:198-209. 
5. Panicker SP, Raychaudhuri B, Sharma P, Tipps R, Mazumdar T, Mal AK, Palomo JM, Vogelbaum MA, Haque SJ. p300- and Myc-mediated regulation of glioblastoma multiforme cell differentiation. Oncotarget 2010; 1:289303.

6. Merzak A, Pilkington GJ. Molecular and cellular pathology of intrinsic brain tumours. Cancer Metastasis Rev. 1997; 16:155-77.

7. Chung CD, Liao J, Liu B, Rao X, Jay P, Berta P, Shuai K. Specific inhibition of Stat3 signal transduction by PIAS3. Science. 1997; 278:1803-05.

8. Nojiri S, Joh T, Miura Y, Sakata N, Nomura T, Nakao H, Sobue S, Ohara H, Asai K, Ito M. ATBF1 enhances the suppression of STAT3 signaling by interaction with PIAS3. Biochem Biophys Res Commun. 2004; 314:97-103.

9. Schmidt D, Müller S. PIAS/SUMO: new partners in transcriptional regulation. Cell Mol Life Sci. 2003; 60:2561-74.

10. Müller S, Ledl A, Schmidt D. SUMO: a regulator of gene expression and genome integrity. Oncogene. 2004; 23:1998-2008.

11. Wible BA, Wang L, Kuryshev YA, Basu A, Haldar S, Brown AM. Increased $\mathrm{K}+$ efflux and apoptosis induced by the potassium channel modulatory protein $\mathrm{KChAP} /$ PIAS3beta in prostate cancer cells. J Biol Chem. 2002; 277:17852-62.

12. Wang L, Banerjee S. Differential PIAS3 expression in human malignancy.Oncol Rep. 2004; 11:1319-24.

13. Murugesan G, Sa G, Fox PL. High-density lipoprotein stimulates endothelial cell movement by a mechanism distinct from basic fibroblast growth factor. Circ Res. 1994; 74:1149-56.

14. Perreau J, Lilienbaum A, Vasseur M, Paulin D. Nucleotide sequence of the human vimentin gene and regulation of its transcription in tissues and cultured cells. Gene. 1988; 62(1):7-16.

15. Shiras A, Bhosale A, Shepal V, Shukla R, Baburao VS, Prabhakara K, Shastry P. A unique model system for tumor progression in GBM comprising two developed human neuro-epithelial cell lines with differential transforming potential and coexpressing neuronal and glial markers. Neoplasia. 2003; 5:520-32.

16. Mennel HD, Lell B. Ganglioside (GD2) expression and intermediary filaments in astrocytic tumors. Clin Neuropathol. 2005; 24:13-8.

17. Yang HY, Lieska N, Shao D, Kriho V, Pappas GD. Proteins of the intermediate filament cytoskeleton as markers for astrocytes and human astrocytomas. Mol Chem Neuropathol. 1994; 21:155-76.

18. Hoelzinger DB, Mariani L, Weis J, Woyke T, Berens TJ, McDonough WS, Sloan A, Coons SW, Berens ME. Gene expression profile of glioblastoma multiforme invasive phenotype points to new therapeutic targets. Neoplasia. 2005; 7:7-16.
19. Van Dyck F, Delvaux EL, Van de Ven WJ, Chavez MV. Repression of the Transactivating Capacity of the Oncoprotein PLAG1 by SUMOylation. J Biol Chem. 2004; 279:36121-31.

20. Reinhardt A, Hubbard T. Using neural networks for prediction of the subcellular location of proteins. Nucleic Acids Res. 1998; 26:2230-6.

21. Knuesel M, Cheung HT, Hamady M, Barthel KK, Liu X. A method of mapping protein sumoylation sites by mass spectrometry using a modified small ubiquitin-like modifier 1 (SUMO-1) and a computational program. Mol Cell Proteomics. 2005; 4:1626-36.

22. Gilles C, Polette M, Mestdagt M, Nawrocki-Raby B, Ruggeri P, Birembaut P, Foidart JM. Transactivation of vimentin by beta-catenin in human breast cancer cells. Cancer Res. 2003; 63:2658-64.

23. Lang SH, Hyde C, Reid IN, Hitchcock IS, Hart CA, Bryden AA, Villette JM, Stower MJ, Maitland NJ. Enhanced expression of vimentin in motile prostate cell lines and in poorly differentiated and metastatic prostate carcinoma. Prostate. 2002; 52:253-63.

24. Singh S, Sadacharan S, Su S, Belldegrun A, Persad S, Singh G. Overexpression of vimentin: role in the invasive phenotype in an androgen-independent model of prostate cancer. Cancer Res. 2003; 63:2306-11.

25. Hendrix MJ, Seftor EA, Chu YW, Trevor KT, Seftor RE. Role of intermediate filaments in migration, invasion and metastasis. Cancer Metastasis Rev. 1996; 15:507-25.

26. Gilles C, Polette M, Zahm JM, Tournier JM, Volders L, Foidart JM, Birembaut P. Vimentin contributes to human mammary epithelial cell migration. J Cell Sci. 1999; 112:4615-25.

27. Maniotis AJ, Chen CS, Ingber DE. Demonstration of mechanical connections between integrins, cytoskeletal filaments, and nucleoplasm that stabilize nuclear structure. Proc Natl Acad Sci U S A. 1997; 94:849-54.

28. Rao J, Li N. Microfilament actin remodeling as a potential target for cancer drug development. Curr Cancer Drug Targets. 2004; 4:345-54. 